Article

\title{
Effects of RAFT Agent on the Selective Approach of Molecularly Imprinted Polymers
}

\section{Saliza Asman ${ }^{1,2, \dagger}$, Sharifah Mohamad ${ }^{1, *}$ and Norazilawati Muhamad Sarih ${ }^{1, \dagger}$}

1 Department of Chemistry, Faculty of Science, University of Malaya, Lembah Pantai, 50603 Kuala Lumpur, Malaysia; E-Mails: saliza_asman@yahoo.com (S.A.); nmsarih@um.edu.my (N.M.S.)

2 Department of Science and Mathematics, Faculty of Science, Technology and Human Development, University of Tun Hussein Onn Malaysia, Parit Raja, 86400 Johor, Malaysia

$\dagger$ These authors contributed equally to this work.

* Author to whom correspondence should be addressed; E-Mail: sharifahm@um.edu.my; Tel.: +603-7967-6751; Fax: +603-7967-4193.

Academic Editor: Philipp Vana

Received: 12 July 2014 / Accepted: 2 March 2015 / Published: 6 March 2015

\begin{abstract}
Two types of reversible addition-fragmentation chain transfer molecularly imprinted polymers (RAFT-MIPs) were synthesized using different monomers, which were methacrylic acid functionalized $\beta$-cyclodextrin (MAA- $\beta$-CD) and 2-hydroxyethyl methacrylate functionalized $\beta$-cyclodextrin (HEMA- $\beta-C D$ ), via reversible addition-fragmentation chain transfer (RAFT) polymerization, and were represented as RAFT-MIP(MAA- $\beta-C D)$ and RAFT-MIP(HEMA- $\beta$-CD), respectively. Both RAFT-MIPs were systematically characterized using Fourier Transform Infrared Spectroscopy (FTIR), Field Emission Scanning Electron Microscopy (FESEM), Brunauer-Emmett-Teller (BET), and rebinding experimental study. The results were compared with MIPs synthesized via the traditional radical polymerization (TRP) process, and were represented as MIP(MAA- $\beta-C D)$ and MIP(HEMA- $\beta-C D)$. Morphology results show that RAFT-MIP(MAA- $\beta-C D)$ has a slightly spherical feature with a sponge-like form, while RAFT-MIP(HEMA- $\beta-C D)$ has a compact surface. BET results show that the surface area of RAFT-MIP(MAA- $\beta-C D)$ is higher than MIP(MAA- $\beta-C D)$, while the RAFT-MIP(HEMA- $\beta-C D)$ surface area is lower than that of MIP(HEMA- $\beta-C D)$. Rebinding experiments indicate that the RAFT agent increased the binding capacity of RAFT-MIP(MAA- $\beta-C D)$, but not of RAFT-MIP(HEMA- $\beta-C D)$, which proves that a RAFT
\end{abstract}


agent does not always improve the recognition affinity and selective adsorption of MIPs. The usability of a RAFT agent depends on the monomer used to generate potential MIPs.

Keywords: molecularly imprinted polymer; methacrylic acid functionalized $\beta$-cyclodextrin; 2-hydroxyethyl methacrylate functionalized $\beta$-cyclodextrin; RAFT agent

\section{Introduction}

Molecular imprinting is a versatile approach in making synthetic receptors with tailor-made recognition sites. A molecularly imprinted polymer (MIP) is typically synthesized via the copolymerization of a monomer and cross-linker in the presence of a template molecule and a suitable porogenic solvent. After the polymerization process, the template is removed from the cross-linked polymer network. This removal will lead to three-dimensional cavities that are complementary in size, shape, and chemical functionality to the template. The resulting MIP serves high specificity and selectivity for the template, and is favorable towards mechanical, thermal, and chemical stabilities [1,2]. It is clearly suitable for various applications, such as in separations [3], chemical sensors [4], selective catalysis [5], and hybrid membranes [6].

The traditional radical polymerization (TRP) process is a major technique used to prepare MIPs due to the fact that it can be carried out under mild reaction conditions, is tolerant of protonic impurities, including water, and it can be used for a wide range of monomers [7]. However, TRP has little control over the polymer chains and network structures, which provide cross-linked polymer networks with heterogeneous structures [8]. The preparation of molecularly imprinted polymers (MIPs) with heterogeneous network structures would greatly affect the internal binding sites, which might be responsible for some of the inherent drawbacks of MIPs, such as the broad binding sites' heterogeneity, relatively low affinity, and reduced selectivity [9]. TRP allows for limited control over the polymer growth processes and molecular architectures of the polymeric products when it is applied for the synthesis of structurally non-complex polymer architectures, such as linear macromolecules [10,11].

To overcome these drawbacks, the reversible deactivation radical polymerization (RDRP) process can be used to prepare polymers with well-defined structures [12]. The problematic chain termination in TRP can be minimized using living radical initiators, resulting in a more constant and much slower rate of polymer chain growth. This improves both chain growth and chain relaxation rates, leading to a homogeneous polymer network structures. The application of RDRP in molecular imprinting has been proven to provide MIPs with improved binding properties, such as faster binding kinetics, higher binding capacities, larger binding association constants, and significantly higher affinity site densities [13]. RDRP has been widely utilized to synthesis MIPs in various polymerization methods such as surface grafting [14,15], suspension [16], precipitation [9,13,17], emulsion [18], and core-shell [19-21] polymerizations.

RDRP in the bulk polymerization method for the synthesis MIPs has also been reported in previous literature [22-24]. It has been reported that the method was successfully enhanced, with a higher specific template binding when compared to the ones obtained from the prepared TRP bulk polymerization process. It can be concluded that the RDRP bulk polymerization process improves the 
binding properties of MIPs. Bulk polymerization is the most popular and universal method for synthesizing MIPs [25]. It is fast, simple, and does not require advanced skills or sophisticated instruments [2]. The MIP was prepared by mixing all of the components (template, monomer, cross-linker, solvent and initiator), and then bulk polymerization took place. The resulting MIP was ground and sieved, producing bulk polymer particles [2]. However, recent reports have discussed the fact that MIPs obtained via RDRP have low binding capacities and template binding properties when compared to conventional MIPs. There is speculation that, due to the fast gelation process in RDRP, the mobility of the chemical species is greatly restricted, leading directly to a heavily interrupted equilibrium between the dormant species and the active radicals in RAFT's mechanism [26,27]. Basically, it was proven that the application of RDRP in molecular imprinting does not always improve the binding properties of the MIPs.

The reversible addition-fragmentation chain transfer (RAFT) polymerization process, which is a type of RDRP method [28], was selected for this study. Among RDRP methods, RAFT polymerization is the most versatile [29], especially in terms of providing living characteristics to the radical polymerization [30,31], making it compatible with almost all TRP monomers [32]. To compare with other RDRP methods, such as atom transfer radical polymerization (ATRP), the RAFT technique does not involve any metal catalyst, hence, there is no trace of metal contaminants in the final products, unlike the ATRP method $[19,33]$. RAFT polymerization allows the synthesis of several functional polymeric materials and the design of hyperbranched polymers [34-37]. Due to its advantages, RAFT polymerization has been used to prepare cross-linked polymers, such as MIPs synthesis [20,38,39] and other homogeneous polymer networks [40,41].

The controllability of the RAFT polymerization lies in the use of RAFT agent (normally a dithioester) [9]. Figure S1 shows the general structure of RAFT agent with dithioester structure. The R acts as a free radical leaving group and reinitiates polymerization, while the role of $\mathrm{Z}$ is to modify addition and fragmentation rate. In this study, cumyl dithiobenzoate (CDB) is a type of dithioester was selected as a RAFT agent, and it is generally used in MIP synthesis [9,27,38]. In fact, CDB had higher reactivity when the $\mathrm{Z}$ group is a conjugated group, in which it is a phenyl group, and thus has profound impact on the RAFT polymerization process [17].

The $\beta$-CD is a cyclic oligosaccharide, consisting of seven glucose units and residues linked with $\alpha-(1,4)$ bonds, which possess the primary hydroxyl groups on the narrow (primary) side, a secondary hydroxyl inner cavity, and a hydrophilic external surface [42]. The truncated cone-shaped molecule of the $\beta-C D$ forms an inclusion compound with various analytes via "host-guest interaction". Thus, the orientation of the $\beta$-CD molecule residues in MIPs is suitable for the cooperative binding of the templates [43]. The modification of the monomer with $\beta-\mathrm{CD}$ is a promising step, as there is a lack of specific binding sites in the cavities created by imprinting. By linking several functional groups of monomer to $\beta-\mathrm{CD}$, the recognition ability could be improved, which increases the binding capacity of MIPs [44].

We have successfully synthesized two types of reversible addition-fragmentation chain transfer molecularly imprinted polymers (RAFT-MIPs) using different monomers, which were methacrylic acid functionalized $\beta$-cyclodextrin (MAA- $\beta-\mathrm{CD}$ ) and 2-hydroxyethyl methacrylate functionalized $\beta$-cyclodextrin (HEMA- $\beta$-CD) via RAFT polymerization, represented as reversible addition-fragmentation chain transfer molecularly imprinted polymer methacrylic acid functionalized $\beta$-cyclodextrin, 
RAFT-MIP(MAA- $\beta$-CD) and reversible addition-fragmentation chain transfer molecularly imprinted polymer 2-hydroxyethyl methacrylate functionalized $\beta$-cyclodextrin, RAFT-MIP(HEMA- $\beta$-CD), respectively, for the selective binding of benzylparaben $(\mathrm{BzP})$. This study aimed to investigate the potential of applying RAFT agent in the synthesis of imprinted polymers, based on the selective binding properties. A detailed study involving both RAFT-MIPs was then compared to the traditional MIPs.

\section{Experimental Section}

\subsection{Materials}

Benzylparaben (BzP), butylparaben (BuP), propylparaben (PrP), ethylparaben (EtP), methylparaben (MeP), toluene-2,4-diisocyanate (TDI), methacrylic acid (MAA), 2-hydroxylethyl methacrylate (HEMA), trimethylolpropane trimethacrylate (TRIM), benzyol peroxide (BPO), dimethylacetamide (DMAC), methanol $(\mathrm{MeOH})$, acetic acid, cumyl dithiobenzoate (CDB), and dibutyltin dilaurate (DBTDL) were procured from Sigma-Aldrich chemicals (St. Louis, MO, USA). $\beta$-cyclodextrin ( $\beta$-CD) (99\%) was bought from Acros (Geel, Belgium). Other reagents and chemicals were of analytical reagent grade and were used as received without further purification. Distilled water was used throughout the experiments.

\subsection{Instruments}

Fourier transform infrared (FTIR) spectra of the polymers were recorded using a Fourier Transform Infrared (FTIR) spectrometer (Perkin Elmer, Waltham, MA, USA) in KBr pellets. The analysis of the Brunauer-Emmett-Teller (BET) surface area and porous properties of the polymers were determined from the nitrogen adsorption-desorption analysis at $77 \mathrm{~K}$, using a surface area analyzer (Quantachrome, Boynton Beach, FL, USA). The specific surface areas, average pore diameters, and total pore volumes of polymers were calculated using the Brunauer-Emmett-Teller (BET) method, Barrett-Joyner-Halenda (BJH) method, and Dubinin-Radushkevich (D-R) plots, respectively. The morphology and surface structure of the polymers were shown using the JSM-6390 Field Emission Scanning Electron Microscope (FESEM) from JEOL (Tokyo, Japan). The proton Nuclear Magnetic Resonance ( ${ }^{1} \mathrm{H}$ NMR) spectra of the MAA- $\beta-C D$ and HEMA- $\beta-C D$ samples, in dimethyl sulfoxide (DMSO), were recorded on a Lambda JEOL 400 MHz Fourier Transform NMR (FT-NMR) spectrometer (Bruker, Fällanden, Switzerland) at room temperature. The rebinding experiments were conducted using a Shimadzu Ultraviolet-Visible (UV-Vis) spectroscopy recording spectrophotometer (Shimadzu, Tokyo, Japan), equipped with $1 \mathrm{~cm}$ quartz cells.

\subsection{Preparation of $M A A-\beta-C D$ and HEMA- $\beta-C D$ Monomers}

The synthesis of MAA- $\beta-C D$ and HEMA- $\beta-C D$ monomers was adopted from the method of Sreenivasan [45]. The molar concentration was chosen in this case, using a stoichiometry ratio of 0.5 M MAA or HEMA: $1 \mathrm{M}$ TDI: $0.5 \mathrm{M} \beta$-CD. Firstly, TDI was mixed with MAA or HEMA in $20 \mathrm{~mL}$ DMAC solvent. Then, $0.02 \mathrm{~mL}$ of DBTDL catalyst was added into the mixture. The solution was magnetically stirred at room temperature under $\mathrm{N}_{2}$ gas conditions for an hour. Later, a calculated amount of $\beta$-CD and $5 \mathrm{~mL}$ of DMAC solvent were added after the mixture became homogeneous. The 
mixture was continuously stirred for $2 \mathrm{~h}$. The formation of MAA- $\beta-\mathrm{CD}$ and HEMA- $\beta-\mathrm{CD}$ monomers was confirmed using FTIR and ${ }^{1} \mathrm{H}$ NMR spectroscopies, with the results being summarized below. The proton signal is assigned as well (Figure 1), with its expected structure shown (Figure 2). The synthesis reactions for the two monomers are shown in Figures S2 and S3 of the Supplementary Data.

(a)

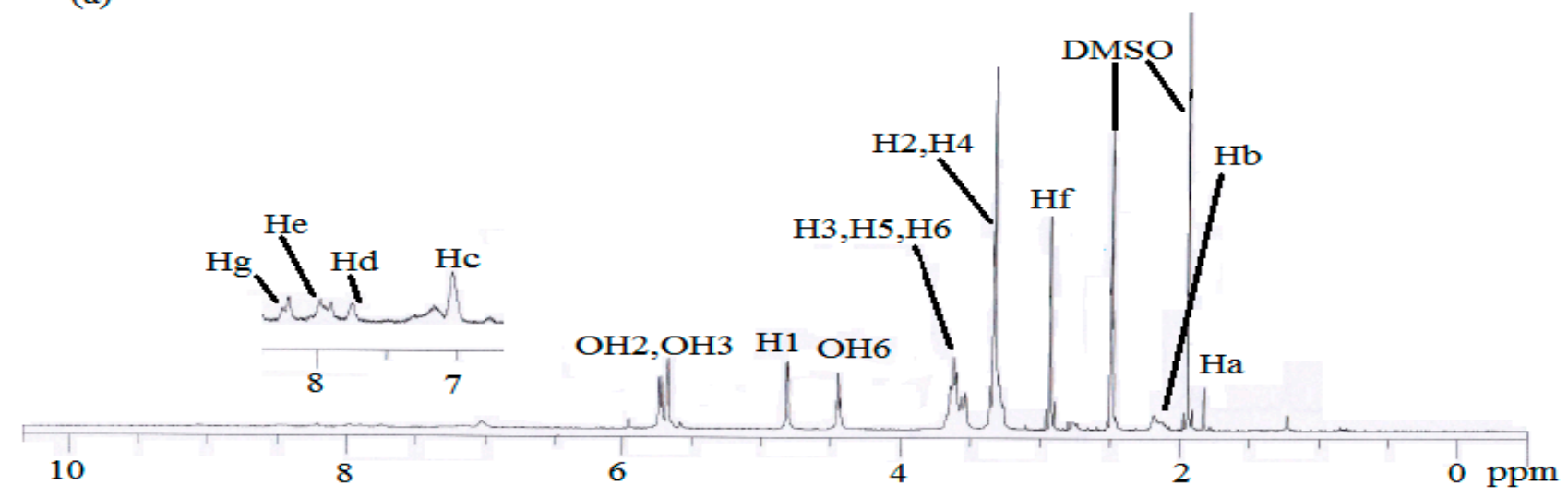

(b)

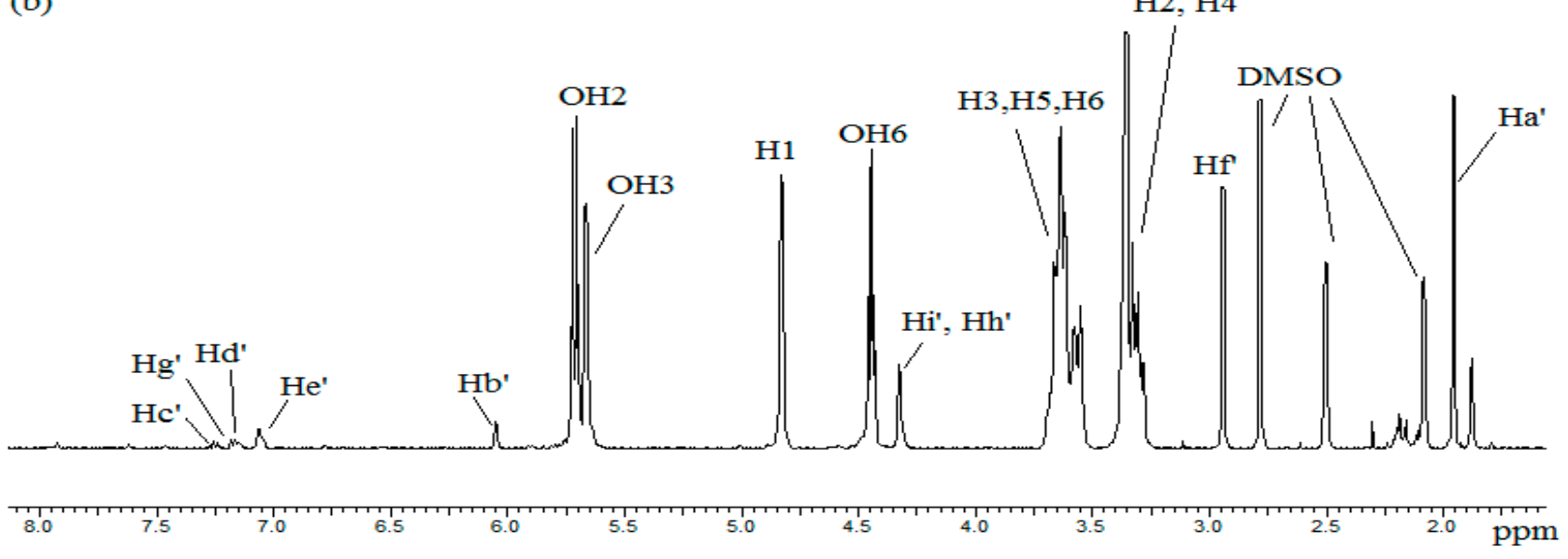

Figure 1. ${ }^{1} \mathrm{H}$ NMR spectra of (a) MAA- $\beta-\mathrm{CD}$; and (b) HEMA- $\beta-C D$.

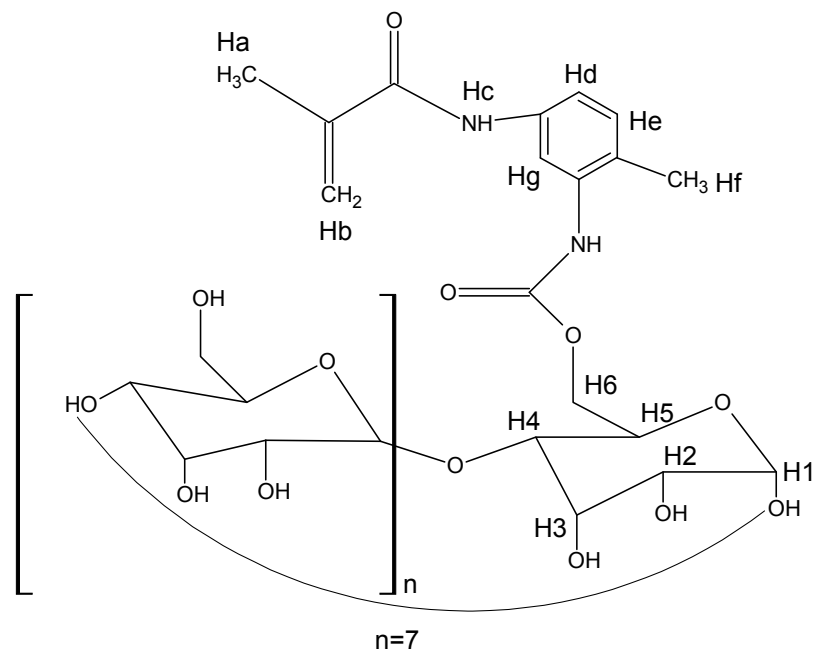

(a)

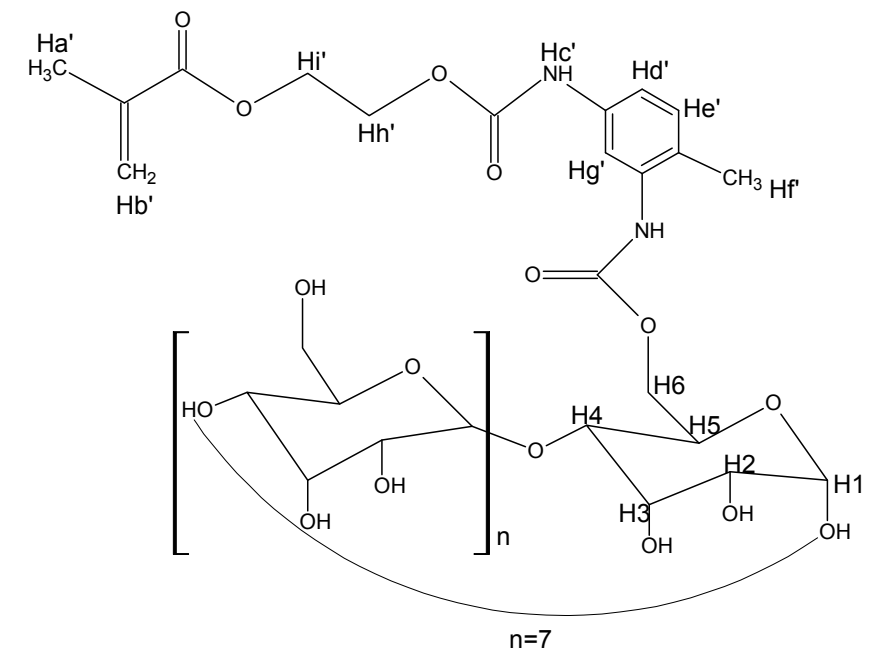

(b)

Figure 2. Structures of (a) MAA- $\beta-C D$; and (b) HEMA- $\beta-C D$. 
(MAA- $\beta-C D)$ IR (KBR), cm ${ }^{-1} 3296(\mathrm{O}-\mathrm{H}), 2925(\mathrm{C}-\mathrm{H}), 1735$ (C=O stretch), $1611(\mathrm{C}=\mathrm{C})$, $1151(\mathrm{C}-\mathrm{N}), 1078\left(\mathrm{C}=\mathrm{O}\right.$ bend), $1023(\mathrm{C}-\mathrm{O}) .(\mathrm{HEMA}-\beta-\mathrm{CD}) \mathrm{IR}(\mathrm{KBr}), \mathrm{cm}^{-1} 3421(\mathrm{O}-\mathrm{H}), 2957(\mathrm{C}-\mathrm{H})$, $1713(\mathrm{C}=\mathrm{O}$ stretch), $1163(\mathrm{C}=\mathrm{C}), 1162(\mathrm{C}-\mathrm{N}), 1077(\mathrm{C}=\mathrm{O}$ bend), $1029(\mathrm{C}-\mathrm{O})$. (MAA- $\beta-\mathrm{CD})$ $\mathrm{H}^{1} \mathrm{NMR} / \mathrm{ppm},\left(400 \mathrm{MHz}, \mathrm{DMSO}-d_{6}, \delta\right): \mathrm{Ha}$ (1.94), Hb (5.7 and 5.8), Hc (7.27), Hd (7.92), He (8.22), Hf (2.52), Hg (8.42), OH2-OH3 (5.74-5.71), H1 (4.81), OH6 (4.45), H2 (3.33), H3 (3.62), H4 (3.36), H5 (3.60) and H6 (3.65). (HEMA- $\beta-C D) \mathrm{H}^{1} \mathrm{NMR} / \mathrm{ppm}$, (400 MHz, DMSO-d6, $\delta$ ): Ha' (1.79), Hb' (6.18), Hc' (7.27), Hd' (7.35), He' (7.43), Hf' (2.96), Hg' (8.56), Hh' (4.31), Hi' (4.35), OH2-OH3 (5.75-5.64), H1 (4.83), OH6 (4.48), H2 (3.28), H3 (3.82), H4 (3.45), H5 (3.66), H6 (3.46).

\subsection{Synthesis of RAFT-MIPs/RAFT-NIPS}

As for the synthesis of RAFT-MIP(MAA- $\beta-C D)$, as RAFT-MIP1 (Scheme 1), the BzP template $(0.14 \mathrm{mmol}, 0.032 \mathrm{~g})$ was dissolved in $10 \mathrm{~mL}$ of DMAC, containing MAA- $\beta-C D$ monomer (0.56 mmol, $0.757 \mathrm{~g})$, TRIM (2.80 mmol, $0.894 \mathrm{~mL})$ as cross-linker, cumyl dithiobenzoate (CDB) $(1.24 \mathrm{mmol}, 0.327 \mathrm{~g})$ as RAFT agent, and BPO $(0.6 \mathrm{mmol}, 0.145 \mathrm{~g})$ as initiator. The synthesis of RAFT-MIP(HEMA- $\beta-C D$ ) as RAFT-MIP2 (Scheme 1) was carried out under similar conditions, using a HEMA- $\beta$-CD monomer $(0.56 \mathrm{mmol}, 0.806 \mathrm{~g})$. The solution was sealed and purged with $\mathrm{N}_{2}$ gas for at least $10 \mathrm{~min}$ before placing it in a water bath at $70{ }^{\circ} \mathrm{C}$ overnight. After polymerization, the obtained RAFT-MIPs were completely crushed, ground, and wet-sieved. Then, the RAFT-MIPs particles were washed with a mixture of methanol/acetic acid $(v / v, 9: 1)$ until the BzP in the eluate could no longer be detected at wavelength of $258 \mathrm{~nm}$ by the UV-Vis spectrophotometer. Then, the particles were washed with methanol to remove any residual acetic acid and dried under vacuum at $80^{\circ} \mathrm{C}$.

The reversible addition-fragmentation chain transfer-non-molecularly imprinted polymers (RAFT-NIPs) were divided into reversible addition-fragmentation chain transfer non-molecularly imprinted polymer methacrylic acid functionalized $\beta$-cyclodextrin, RAFT-NIP(MAA- $\beta$-CD), and reversible addition-fragmentation chain transfer non-molecularly imprinted polymer 2-hydroxyethyl methacrylate functionalized $\beta$-cyclodextrin, RAFT-NIP(HEMA- $\beta-C D)$, as RAFT-NIP1 and RAFT-NIP2, respectively, as they were synthesized without the BzP template as reference.

The traditional MIPs and NIPs (omitted RAFT agent) were synthesized using the TRP process, where molecularly imprinted polymer methacrylic acid functionalized $\beta$-cyclodextrin, MIP(MAA- $\beta-C D)$, and molecularly imprinted polymer 2-hydroxyethyl methacrylate functionalized $\beta$-cyclodextrin, MIP(HEMA- $\beta-C D)$, were represented as MIP1 and MIP2, while non-molecularly imprinted polymer methacrylic acid functionalized $\beta$-cyclodextrin, NIP(MAA- $\beta-C D)$, and non-molecularly imprinted polymer 2-hydroxyethyl methacrylate functionalized $\beta$-cyclodextrin, NIP(HEMA- $\beta$-CD), were represented as NIP1 and NIP2, respectively.

$\begin{array}{clc}\begin{array}{c}\text { MAA- } \beta-C D \text { or HEMA- } \beta-C D \\ (\text { monomers })\end{array} & + \text { TRIM crosslinker } \\ + & + \text { DMAC porogenic solvent } & \text { RAFT-MIP(MAA- } \beta-C D) \\ \text { Benzylparaben (template) } & + \text { Benzoyl peroxide } \\ & + \text { CDB as RAFT agent } & \text { RAFT-MIP(HEMA- } \beta-C D)\end{array}$

Scheme 1. Preparation of RAFT-MIPs. 


\subsection{Rebinding Experiments}

In order to estimate the binding selectivity of imprinted polymers for $\mathrm{BzP}$, other parabens, such as BuP, PrP, EtP, and MeP (Figure 3), were chosen as the competitive compounds, as their chemical structures are analogous to BzP.<smiles>O=C(OCc1ccccc1)c1ccc(O)cc1</smiles>

(a)<smiles>CCCOC(=O)c1ccc(O)cc1</smiles>

(c)<smiles>CCCCOC(=O)c1ccc(O)cc1</smiles>

(b)<smiles>CCOC(=O)c1ccc(O)cc1</smiles>

(d)<smiles>COC(=O)c1ccc(O)cc1</smiles>

(e)

Figure 3. Types of parabens: (a) BzP; (b) BuP; (c) PrP; (d) EtP; and (e) MeP.

An amount of $0.05 \mathrm{~g}$ of polymer was incubated in $20 \mathrm{~mL}$ of aqueous solution, containing $10 \mathrm{mg} / \mathrm{L}$ of the selected substrate solution. The mixture was shaken for an hour. The concentration of each analogue was determined individually using a UV-Vis spectrophotometer with the detection wavelength of $258 \mathrm{~nm}$ for BzP, $256 \mathrm{~nm}$ for PrP, and $255 \mathrm{~nm}$ for EtP, MeP, and BuP.

The amount of substrate bound to the polymer $(Q)$ was calculated using the following equation:

$$
Q=V\left(C_{i}-C_{f}\right)
$$

where $C_{i}$ and $C_{f}$ represent the initial and final concentrations $(\mathrm{mg} / \mathrm{L})$, respectively and $V$ is the volume (L) of the solution.

\section{Results and Discussion}

\subsection{Characterization of RAFT-MIPs and MIPS}

The imprinted polymers were characterized using FTIR by comparing them with their respective monomers. FTIR spectrum of the MAA- $\beta-\mathrm{CD}$ monomer (Figure 4a) demonstrated that the $v[\mathrm{O}-\mathrm{H}]$ stretching for the $\beta-\mathrm{CD}$ molecule was assigned to the peak at $3296 \mathrm{~cm}^{-1}$, while the $v[\mathrm{C}=\mathrm{C}]$ and $v[\mathrm{C}=\mathrm{O}]$ of the MAA molecule corresponded to the peaks at $1611 \mathrm{~cm}^{-1}$ and $1735 \mathrm{~cm}^{-1}$, respectively. The presence of $v\left[\mathrm{CH}_{3}\right]$ of MAA was confirmed by the absorption peaks at $2929 \mathrm{~cm}^{-1}$ and $1409 \mathrm{~cm}^{-1}$. 
The peaks around 939-528 $\mathrm{cm}^{-1}$ indicated the presence of $\alpha-(1,4)$ glucopyranose of $\beta-\mathrm{CD}$. The peak at $1023 \mathrm{~cm}^{-1}$ is representative of $v[\mathrm{C}-\mathrm{O}]$ stretching, confirming the fact that the $-\mathrm{OH}$ group of MAA and one of the primary $-\mathrm{OH}$ groups of $\beta-\mathrm{CD}$ were covalently bonded with the $-\mathrm{NCO}$ group of TDI (linker). The $v[\mathrm{C}-\mathrm{N}]$ stretching was represented by the peak at $1151 \mathrm{~cm}^{-1}$. The spectra of RAFT-MIP1 (Figure 4b) and MIP1 (Figure 4c) were rather similar, showing a low intensity functional group of $v[\mathrm{O}-\mathrm{H}]$ at $3335-3300 \mathrm{~cm}^{-1}$. The $v[\mathrm{C}-\mathrm{H}], v\left[\mathrm{CH}_{3}\right], v[\mathrm{C}=\mathrm{O}]$, and $v[\mathrm{C}-\mathrm{O}]$ groups were recorded in the range of 2951-2950 $\mathrm{cm}^{-1}, 1457-1461 \mathrm{~cm}^{-1}, 1722-1725 \mathrm{~cm}^{-1}$, and $1142-1140 \mathrm{~cm}^{-1}$, respectively, for RAFT-MIP1 and MIP1.The obtained peaks in the range of $947-578 \mathrm{~cm}^{-1}$, in both spectra of the MIPs, represented the $\alpha-(1,4)$-glucopyranose group of the $\beta$-CD structure [46].

(a)

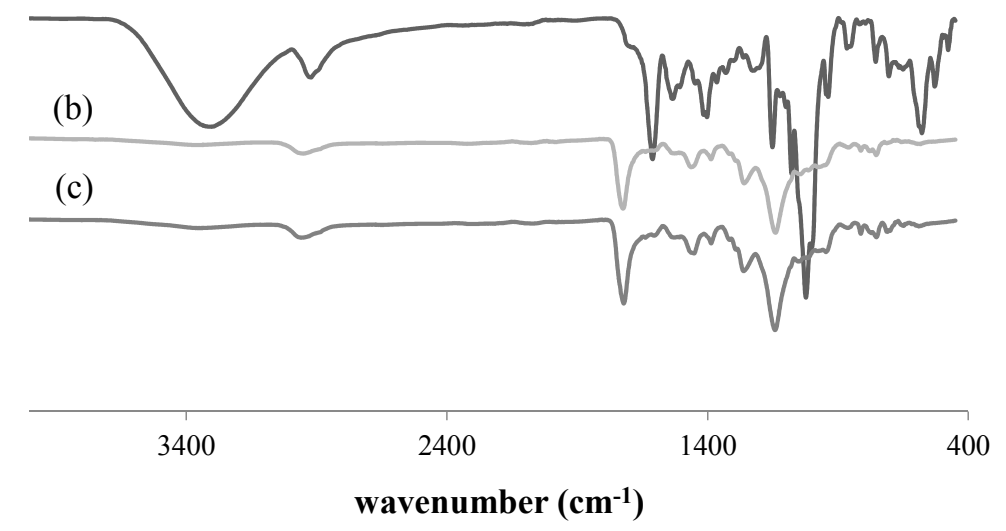

Figure 4. FTIR spectra of (a) MAA- $\beta-C D$; (b) RAFT-MIP1; and (c) MIP1.

The spectrum of HEMA- $\beta-C D$ monomer (Figure 5a) showed that the peaks for $\beta$-CD were observed at $3421 \mathrm{~cm}^{-1}$ and $940-526 \mathrm{~cm}^{-1}$, corresponding to the multiple $v[\mathrm{O}-\mathrm{H}]$ groups and $\alpha-(1,4)$ glucopyranose, respectively. The peaks for HEMA were recorded at $1612 \mathrm{~cm}^{-1}$ and $1713 \mathrm{~cm}^{-1}$, respective to the functional groups of $v[\mathrm{C}=\mathrm{C}]$ and $v[\mathrm{C}=\mathrm{O}]$. Meanwhile, the functional group of $v\left[\mathrm{CH}_{3}\right]$ was recorded at the peaks at $2925 \mathrm{~cm}^{-1}$ and $1406 \mathrm{~cm}^{-1}$. A peak at $1023 \mathrm{~cm}^{-1}$ exhibited for $v[\mathrm{C}-\mathrm{O}$ ] group proved that the $-\mathrm{OH}$ group of HEMA and one of the primary $-\mathrm{OH}$ groups of $\beta-\mathrm{CD}$ were covalently bonded with the $-\mathrm{NCO}$ group of TDI. Thus, the $v[\mathrm{C}-\mathrm{N}]$ group corresponded to the peak at $1162 \mathrm{~cm}^{-1}$. This observation is similar for MAA- $\beta-C D$. According to the spectra of RAFT-MIP2 (Figure 5b) and MIP2 (Figure 5c), the $v[\mathrm{O}-\mathrm{H}]$ group had a low intensity around $3342-3313 \mathrm{~cm}^{-1}$. The $v[\mathrm{C}-\mathrm{H}], v\left[\mathrm{CH}_{3}\right], v[\mathrm{C}=\mathrm{O}]$, and $v[\mathrm{C}-\mathrm{O}]$ groups were recorded in the range of $2929-2938 \mathrm{~cm}^{-1}$, 1494-1451 $\mathrm{cm}^{-1}, 1722-1728 \mathrm{~cm}^{-1}$, and $1142-1140 \mathrm{~cm}^{-1}$, respectively. The $\alpha-(1,4)$-glucopyranose group of $\beta-C D$ structure was consistent in the range of $947-578 \mathrm{~cm}^{-1}$.

The polymerization of MIPs was confirmed from the undetected small peaks of $v[\mathrm{C}=\mathrm{C}]$ groups that were supposedly located at $1611-1612 \mathrm{~cm}^{-1}$ due to the occurrence of covalent interaction between the carbon-carbon double bond from the monomer and the cross-linker molecules [9,28]. Furthermore, the carbonyl, methyl, and methylene groups, which demonstrated the strong absorption peaks, were permanently preserved in the MIPs. These IR results confirmed the polymerization of MIPs. The presence of BzP and RAFT agents went undetected, and it was assumed that a large amount of the functional group of TRIM cross-linker in the components of imprinted polymers strongly overlapped the functional group of BzP and RAFT agent molecules. 


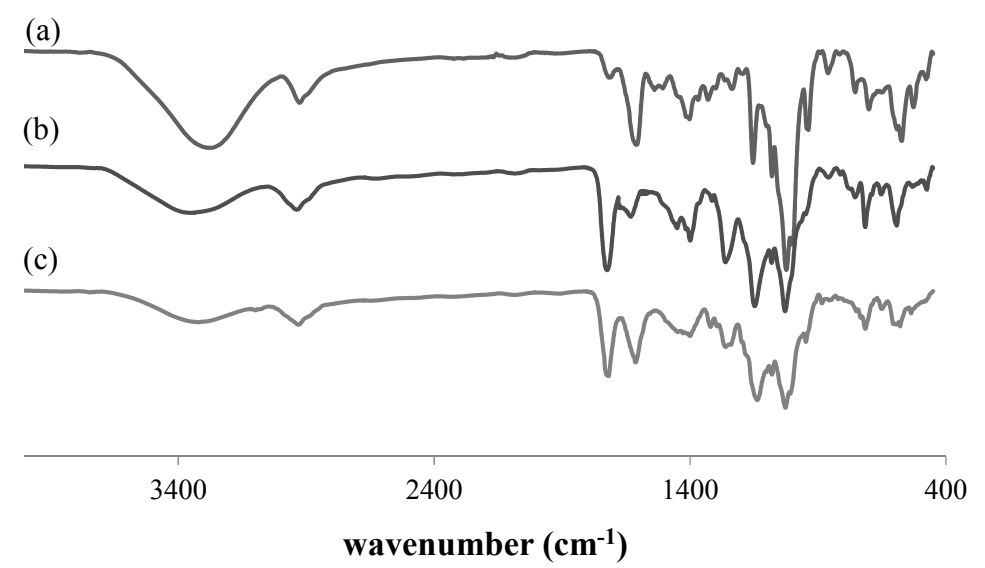

Figure 5. FTIR spectra of (a) HEMA- $\beta-C D$; (b) RAFT-MIP2; and (c) MIP2.

The morphologies of the imprinted polymers (Figure 6) were identified using FESEM characterization at $20,000 \times$ magnification. The imprinted polymers of MAA- $\beta-C D$ and HEMA- $\beta-C D$ were obtained in their own morphologies, indicating that the usage of different monomers strongly affects the texture of the imprinted polymers. The template factor could be affected due to the dissimilar morphologies for MIPs and NIPs. In conclusion, no template existed, and no specific adsorption sites were created on NIPs.

RAFT agent played an important role in MIP synthesis, whereby the RAFT-imprinted polymers and TRP-imprinted polymers were obtained in different morphologies. The effect of RAFT agent could be illustrated in RAFT-MIP1 (Figure 6a), which had slightly spherical and sponge-like textures, while RAFT-NIP1 (Figure 6b) had a rough surface. In the absence of RAFT agent, MIP1 (Figure 6c) was compact, with many pores on its surface. NIP1 (Figure 6d) had a slightly smooth surface compared to MIP1. These different features could be attributed to the intrinsic characteristics of the controlled/living polymerization mechanism of RAFT [9,20], where the morphology of the MIP could be controlled [43].

In this study, different monomers applied with the same RAFT agent showed different morphologies of MIPs synthesis. The imprinted polymers of HEMA- $\beta$-CD showed the RAFT-MIP2 (Figure 6e) and RAFT-NIP2 (Figure 6f) possessing a compact and smooth surface, respectively. The MIP2 (Figure 6g) exhibited a porous surface, while the NIP2 (Figure 6h) had a rough surface. The RAFT agent shrinks the polymer morphology, thus, avoiding the porous structure from being obtained and lowering the binding adsorption of the template. It was speculated that the RAFT agent strongly affected the polymerization process due to the alteration of the morphology on the RAFT-imprinted polymers over TRP imprinted polymers.

The BET data (Table 1) agree with the FESEM images. Table 1 illustrates specific surface area $(S)$, average pore diameter $\left(d_{p}\right)$, and total pore volume $\left(V_{p}\right)$ values for all synthesized imprinted polymers. The $S$ values of the imprinted polymers were lower than the normal range of 100-400 $\mathrm{m}^{2} / \mathrm{g}$ [47], which proved that the $\beta-\mathrm{CD}$ was embedded in the imprinted polymers matrix and decreased $S[44,48]$. All imprinted polymers were regarded as mesoporous particles, as the $d_{p}$ values were around $2-100 \mathrm{~nm}$. Moreover, the $V_{p}$ values of the imprinted polymers were low, which proved that $\beta$-CD was deeply isolated within the internal surfaces of the imprinted polymers [44,49]. Unsurprisingly, the $S$ values of MIPs were higher than those of the NIPs, proving that the recognition sites of the template appeared on the surface of MIPs. 


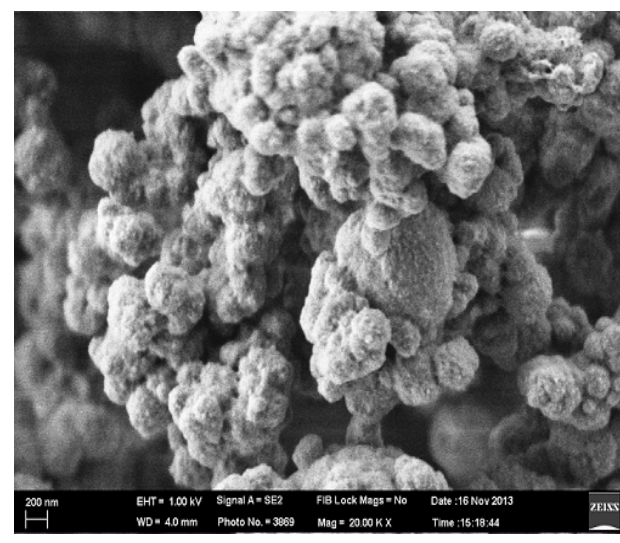

(a)

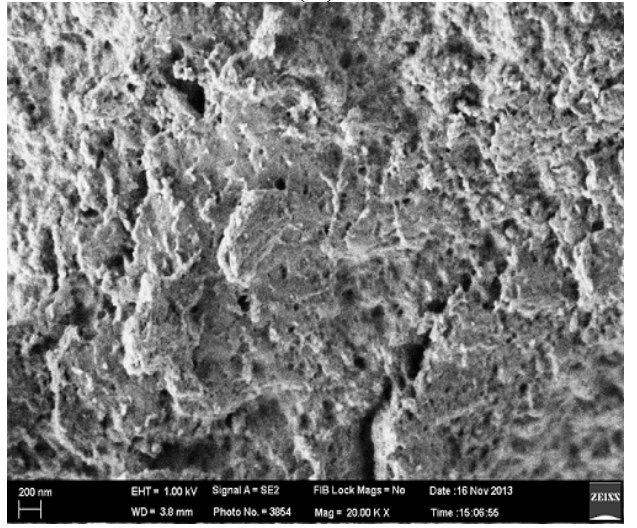

(c)

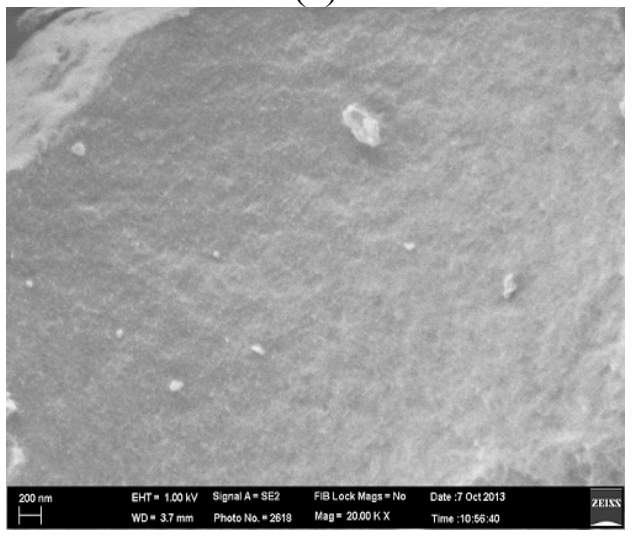

(e)

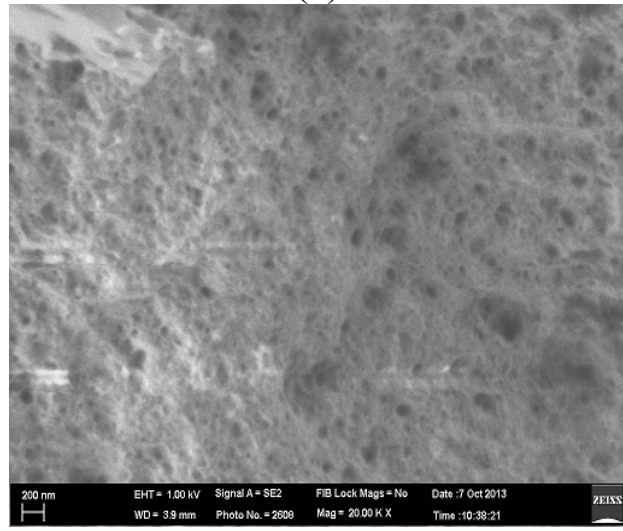

(g)

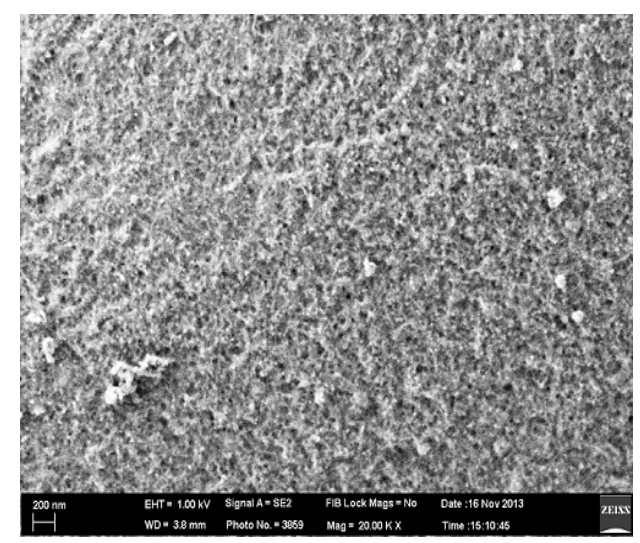

(b)

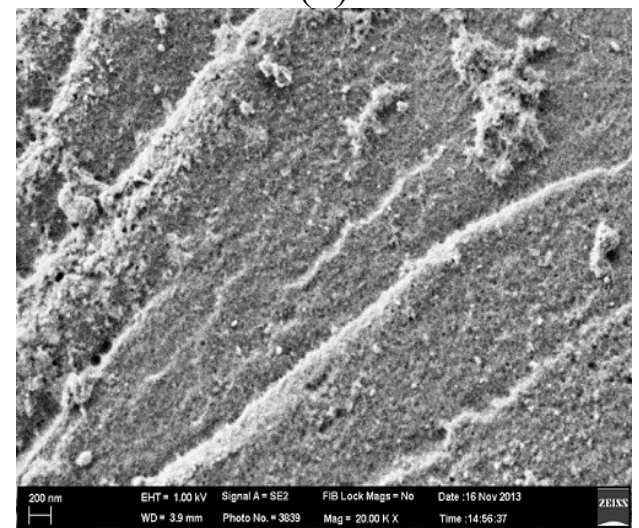

(d)

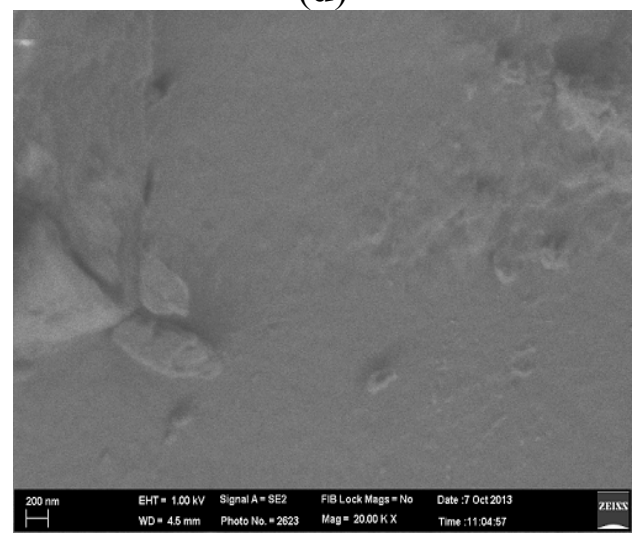

(f)

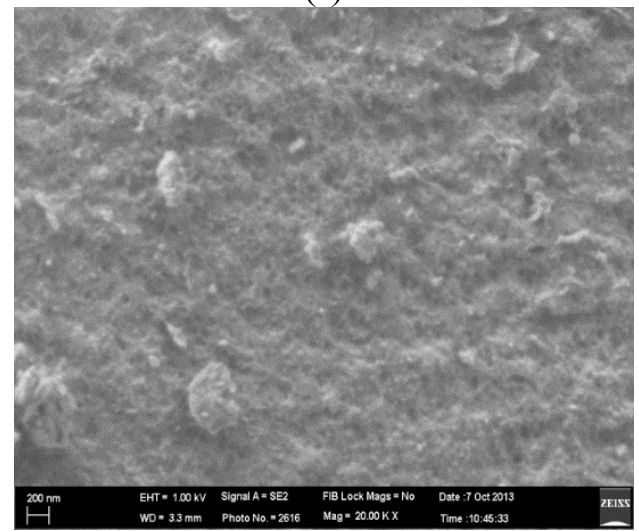

(h)

Figure 6. FESEM micrographs of (a) RAFT-MIP1; (b) RAFT-NIP1; (c) MIP1; (d) NIP1; (e) RAFT-MIP2; (f) RAFT-NIP2; (g) MIP2; and (h) NIP2. 
The effects of RAFT agent could be identified in the variation of BET values between the imprinted polymers of MAA- $\beta-C D$ and HEMA- $\beta-C D$. The $S$ values of the RAFT-MIP1 $\left(11.31 \mathrm{~m}^{2} / \mathrm{g}\right)$ and RAFT-NIP1 $\left(2.22 \mathrm{~m}^{2} / \mathrm{g}\right)$ were higher than those of MIP1 $\left(1.91 \mathrm{~m}^{2} / \mathrm{g}\right)$ and NIP1 $\left(1.57 \mathrm{~m}^{2} / \mathrm{g}\right)$. The presence of RAFT agent may influence the nucleus of the formation particle and the particle growth processes [9]. Therefore, the RAFT agent has controlled the polymerization of MIP by stabilizing the particle growth, and greatly facilitated the adsorption of the template molecules on MIPs. In addition, many researchers have proven that the MAA is suitable to be used in RAFT polymerization processes to synthesize the MIPs [15,18,21]. However, the $S$ values of the RAFT-MIP2 $\left(0.66 \mathrm{~m}^{2} / \mathrm{g}\right)$ and RAFT-NIP2 $\left(0.14 \mathrm{~m}^{2} / \mathrm{g}\right)$ were too low compared to MIP2 $\left(47.68 \mathrm{~m}^{2} / \mathrm{g}\right)$ and NIP2 $\left(5.73 \mathrm{~m}^{2} / \mathrm{g}\right)$. As the values of $S$ were low, non-porous particles could be obtained [33].

Table 1. The values of surface area $(S)$; pore diameter $\left(d_{p}\right)$ and pore volume $\left(V_{p}\right)$ of polymers synthesis.

\begin{tabular}{cccc}
\hline Polymers & Surface Area, $\boldsymbol{S}\left(\mathbf{m}^{2} / \mathbf{g}\right)$ & Pore Diameter, $\boldsymbol{d}_{\boldsymbol{p}}(\mathbf{n m})$ & Pore Volume, $\boldsymbol{V}_{\boldsymbol{p}}\left(\mathbf{c m}^{\mathbf{3}} / \mathbf{g}\right)$ \\
\hline RAFT-MIP1 & 11.31 & 8.67 & $4.20 \times 10^{-4}$ \\
RAFT-NIP1 & 2.22 & 8.21 & $5.75 \times 10^{-4}$ \\
MIP1 & 1.91 & 3.79 & $7.76 \times 10^{-4}$ \\
NIP1 & 1.57 & 6.74 & $5.36 \times 10^{-4}$ \\
RAFT-MIP2 & 0.66 & 6.03 & $3.86 \times 10^{-4}$ \\
RAFT-NIP2 & 0.14 & 7.29 & $4.12 \times 10^{-4}$ \\
MIP2 & 47.68 & 3.32 & $6.05 \times 10^{-3}$ \\
NIP2 & 5.73 & 3.51 & $1.89 \times 10^{-3}$ \\
\hline
\end{tabular}

Figure 7 indicates the $\mathrm{N}_{2}$ sorption isotherms for all imprinted polymers. According to International Union of Pure and Applied Chemistry (IUPAC), all imprinted polymers synthesized via RAFT and TRP polymerization processes would exhibit Type-IV isotherms with hysteresis loops [50]. Type-IV hysteresis loop features parallel and nearly horizontal branches, attributed to the adsorption/desorption in a narrow slit-like process associated with narrow mesoporous characteristics [51]. In all cases, there was a sharp elevation in the adsorbed volume for $P / P_{0}>0.9$. This feature is attributable to the presence of high textural (interparticle) porosity [52], and such particle domains represented substantial adsorption of nitrogen for low surface area mesoporous materials [51]. The origin of $\mathrm{N}_{2}$ sorption isotherms of imprinted polymers of MAA- $\beta-\mathrm{CD}$ (Figure $7 \mathrm{a}-\mathrm{d}$ ) exhibited similar trends of Type-IV isotherms and Type $\mathrm{H} 3$ hysteresis loops, confirming the mesoporosity of the polymers with the presence of heterogeneous open pores [53]. The Type H3 hysteresis loop observed that polymers with aggregates of plate-like particles resulting in slit-shaped pores [54]. The NIP1 (Figure 7d) demonstrated a small hysteresis loop compared to the others, indicating a material with well-defined and regular-shaped pores [55].

In the case of imprinted polymers of HEMA- $\beta-C D$, the effect of RAFT agent is rather obvious. The origin $\mathrm{N}_{2}$ sorption isotherms of RAFT-MIP2 (Figure 7e) and RAFT-NIP2 (Figure 7f) were classified as Type-IV isotherms and had the characteristics of a non-porous materials [16], which are consistent with very low surface area values $\left(<1 \mathrm{~m}^{2} / \mathrm{g}\right)$ (Table 1). The sinusoidal behavior observed in RAFT-MIP2 and RAFT-NIP2 was consistent with such shrinkage effects [16]. The $\mathrm{N}_{2}$ sorption isotherms for MIP2 (Figure 7g) and NIP2 (Figure 7h) indicated a Type-IV isotherms with a hysteresis 
loops of type H2. It is interpreted that the broad hysteresis loops of type $\mathrm{H} 2$ described materials are frequently disordered, with undefined pore size and shape, indicating bottleneck constrictions [55]. Non-closure of hysteresis loops implied incomplete removal of adsorbate from the narrow pores [56].

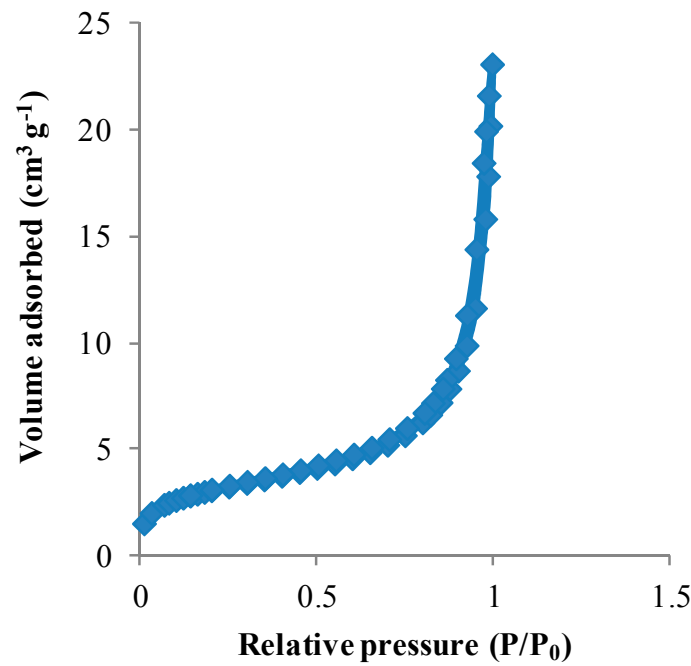

(a)

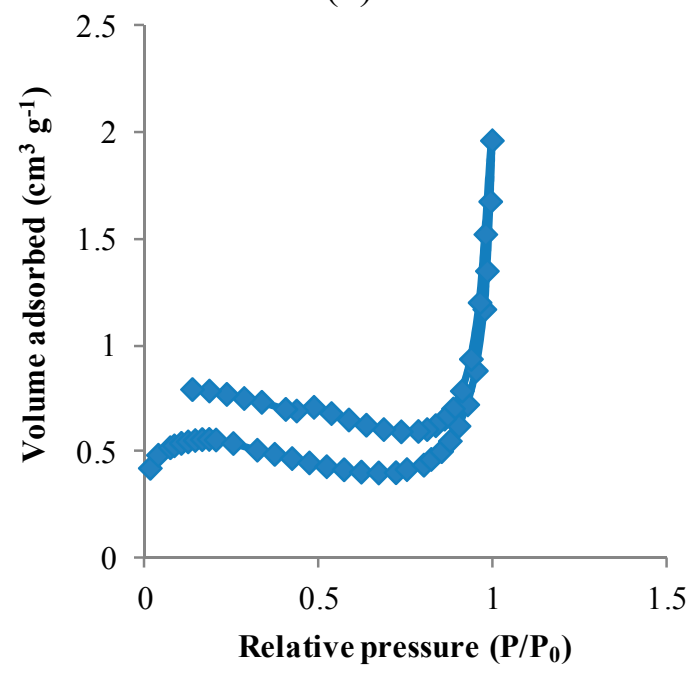

(c)

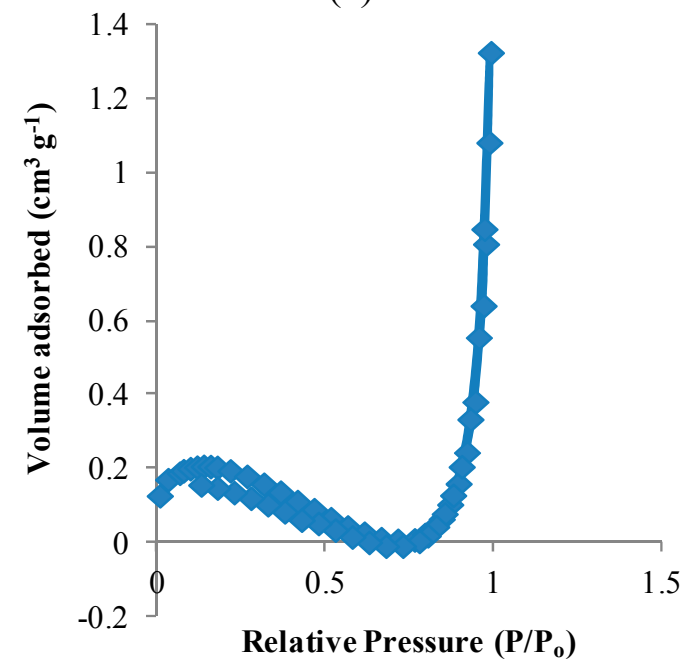

(e)

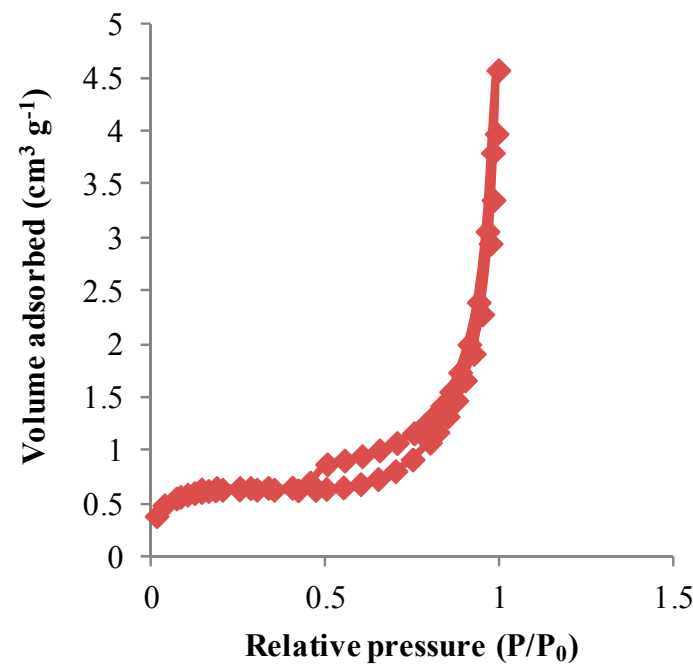

(b)

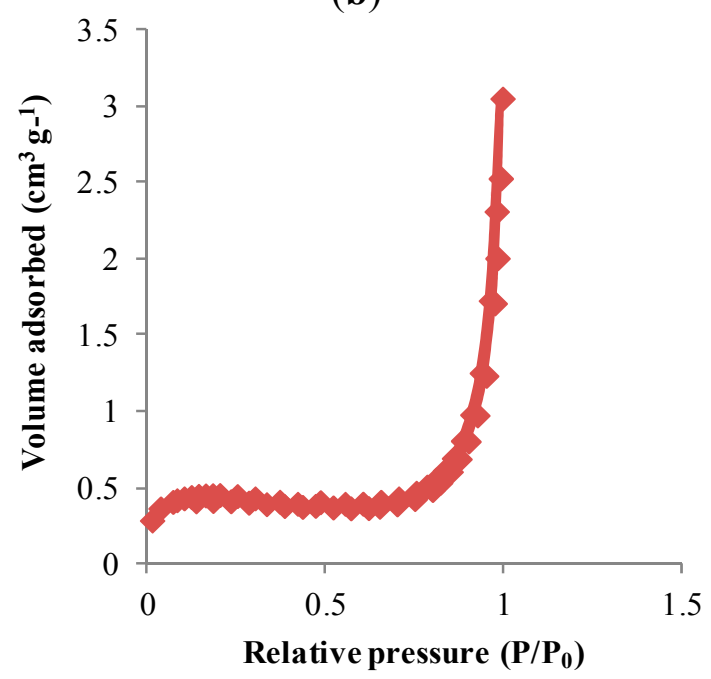

(d)

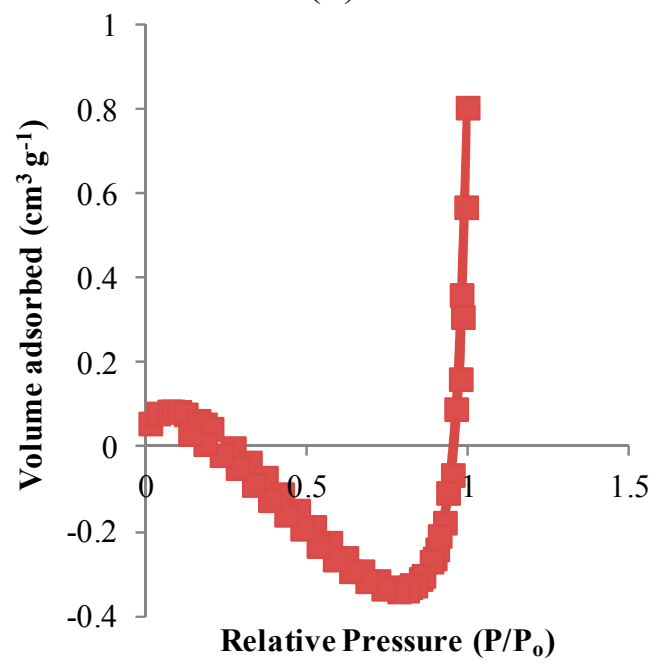

(f)

Figure 7. Cont. 


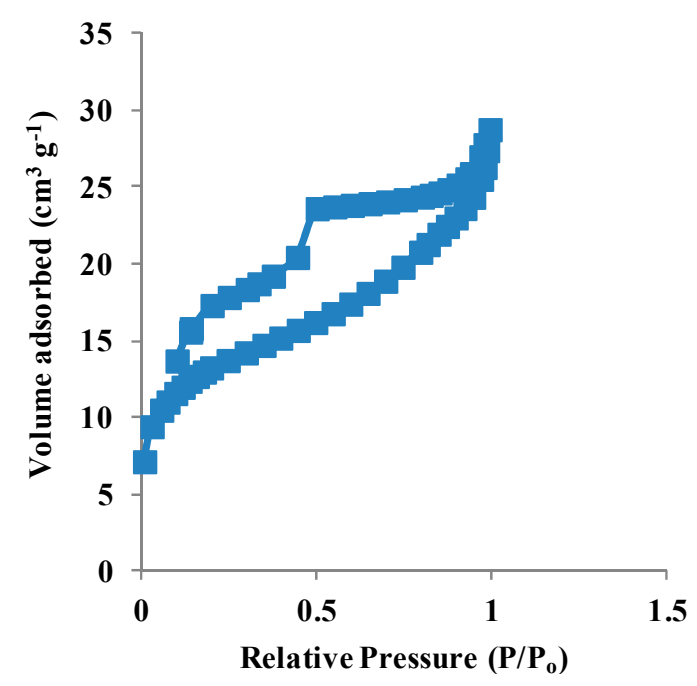

(g)

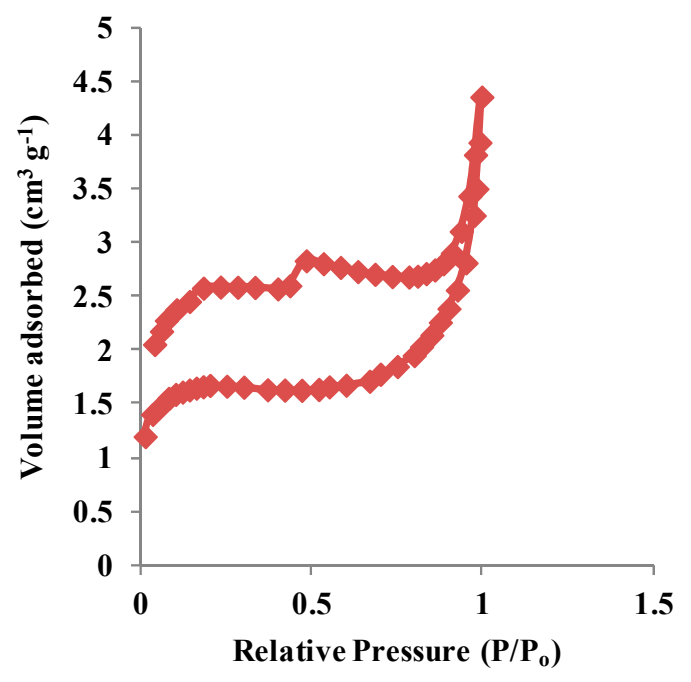

(h)

Figure 7. The $\mathrm{N}_{2}$ adsorption-desorption isotherms for (a) RAFT-MIP1; (b) RAFT-NIP1; (c) MIP1; (d) NIP1; (e) RAFT-MIP2; (f) RAFT-NIP2; (g) MIP2; and (h) NIP2.

\subsection{Binding Characteristics of the Polymers for BzP}

The affinity characteristics of the imprinted polymers for BzP rebinding were determined using binding experiments. The binding affinities of the polymers were identified by the distribution coefficients $\left(K_{d}\right)$ of BzP analytes, between the imprinted polymers and the solution [57]. The equation is defined as:

$$
K_{d}(\mathrm{~L} / \mathrm{g})=C_{p} / C_{f}
$$

where $C_{p}$ is the amount of $\mathrm{Bz} \mathrm{P}$ bound per gram of supports, calculated according to the following equation:

$$
C_{p}(\mathrm{mg} / \mathrm{g})=Q(\mathrm{mg}) / w(\mathrm{~g})
$$

The molecular imprinting factor $(I F)$ was used to evaluate the imprinting effect. $I F$ was calculated according to the equation:

$$
I F=K_{d}(\mathrm{MIP}) / K_{d}(\mathrm{NIP})
$$

The obtained $C_{p}, K_{d}$, and $I F$ values are summarized in Table 2. Theoretically, higher $I F$ value indicated better molecular recognition [33]. It is worth pointing out that RAFT-MIPs and MIPs showed relatively higher affinity capacities towards BzP compared to their respective references. This result shows that larger $K_{d}$ and $I F$ values of RAFT-MIPs and MIPs are partly attributed to higher specific recognition sites left by the template in the imprinted polymer matrix, but are non-specific on the non-imprinted polymers. The values of $C_{p}, K_{d}$, and $I F$ of RAFT-MIP1 were higher than those of MIP1, which proved that RAFT-MIP1 provided an excellent binding capacity and imprinting effect. It is attributed to the fact that the slightly spherical and sponge-like textures of RAFT-MIP1 particles were made up of vast micropores, paving the way for the template to enter the binding sites, located in the interior of the polymer particles, thus, improving the utilization of recognition sites [17]. The high specific surface area (from BET analysis) provided the facility for adsorbing template molecules. As for MIP1, the rough surface and low specific surface area revealed that the imprinted binding sites were placed in the interior of the highly cross-linked polymers, thus, it was difficult for BzP to enter 
the binding sites and decreased the binding capacity of MIP1. However, RAFT-MIP2 resulted in lower binding capacity compared to MIP2. The RAFT-MIP2 morphology showed a compact surface and low specific surface area, indicating the presence of non-porous particles, which were unfavorable for BzP adsorption. Thus, the possibility to increase the binding capacity was low.

Table 2. Recognition of BzP on the polymers (MIPs dosage: $0.05 \mathrm{~g}$; volume of BzP solution: $0.02 \mathrm{~L}$; initial concentration of BzP: $10 \mathrm{mg} / \mathrm{L}$ ).

\begin{tabular}{cccc}
\hline Polymers & $\boldsymbol{C}_{\boldsymbol{p}}(\mathbf{m g} / \mathbf{g})$ & $\boldsymbol{K}_{\boldsymbol{d}}(\mathbf{L} / \mathbf{g})$ & $\boldsymbol{I F}$ \\
\hline RAFT-MIP1 & 4.12 & 2.03 & 7.86 \\
RAFT-NIP1 & 1.92 & 0.26 & - \\
MIP1 & 3.54 & 2.73 & 1.41 \\
NIP1 & 3.36 & 1.94 & - \\
RAFT-MIP2 & 3.10 & 1.13 & 1.31 \\
RAFT-NIP2 & 2.74 & 0.86 & - \\
MIP2 & 3.68 & 1.33 & 1.44 \\
NIP2 & 3.34 & 0.93 & - \\
\hline
\end{tabular}

In order to investigate the binding specificity performance, the capacity adsorption of polymers was compared with other parabens, including BuP, PrP, EtP, and MeP, which shared similar functionalities, but had different functional groups, sizes, and structures. The $K_{d}$ and $I F$ values of all substrates are shown in Table 3. RAFT-MIPs and MIPs exhibited higher binding capacities than RAFT-NIPs and NIPs, due to the recognition sites created by BzP template in RAFT-MIPs and MIPs polymers matrix. Other parabens showed the binding capacities performance due to the presence of certain cross-linking reactivities [9] and polarity properties.

Table 3. $C_{p}(\mathrm{mg} / \mathrm{g}), K_{d}(\mathrm{~L} / \mathrm{g})$ and $I F$ values of the parabens on polymers.

\begin{tabular}{|c|c|c|c|c|c|c|c|c|c|c|}
\hline \multirow[b]{2}{*}{ Parabens } & \multicolumn{2}{|c|}{ RAFT-MIP1 } & \multicolumn{2}{|c|}{ RAFT-NIP1 } & \multirow[b]{2}{*}{ IF } & \multicolumn{2}{|c|}{ MIP1 } & \multicolumn{2}{|c|}{ NIP1 } & \multirow[b]{2}{*}{$I F$} \\
\hline & $\begin{array}{c}C_{p} \\
(\mathrm{mg} / \mathrm{g})\end{array}$ & $\begin{array}{c}K_{d} \\
(\mathrm{~L} / \mathrm{g})\end{array}$ & $\begin{array}{c}C_{p} \\
(\mathrm{mg} / \mathrm{g})\end{array}$ & $\begin{array}{c}K_{d} \\
(\mathrm{~L} / \mathrm{g})\end{array}$ & & $\begin{array}{c}C_{p} \\
(\mathrm{mg} / \mathrm{g})\end{array}$ & $\begin{array}{c}K_{d} \\
(\mathrm{~L} / \mathrm{g})\end{array}$ & $\begin{array}{c}C_{p} \\
(\mathrm{mg} / \mathrm{g})\end{array}$ & $\begin{array}{c}K_{d} \\
(\mathrm{~L} / \mathrm{g})\end{array}$ & \\
\hline $\mathrm{BzP}$ & 4.12 & 2.03 & 1.96 & 0.26 & 7.86 & 3.54 & 2.73 & 3.36 & 1.94 & 1.41 \\
\hline $\mathrm{BuP}$ & 3.62 & 0.68 & 1.58 & 0.11 & 5.99 & 2.97 & 1.09 & 2.86 & 0.96 & 1.15 \\
\hline PrP & 3.07 & 1.05 & 1.60 & 0.19 & 5.54 & 2.22 & 0.29 & 1.88 & 0.22 & 1.31 \\
\hline EtP & 2.63 & 0.39 & 0.59 & - & - & 1.35 & 0.20 & 1.24 & 0.18 & 1.13 \\
\hline $\mathrm{MeP}$ & 1.62 & 0.17 & - & - & - & 0.53 & 0.04 & 0.44 & 0.03 & 0.83 \\
\hline \multirow[b]{2}{*}{ Parabens } & \multicolumn{2}{|c|}{ RAFT-MIP2 } & \multicolumn{2}{|c|}{ RAFT-NIP2 } & & \multicolumn{2}{|c|}{ MIP2 } & \multicolumn{2}{|c|}{ NIP2 } & \\
\hline & $\begin{array}{c}C_{p} \\
(\mathrm{mg} / \mathrm{g})\end{array}$ & $\begin{array}{c}K_{d} \\
(\mathrm{~L} / \mathrm{g})\end{array}$ & $\begin{array}{c}C_{p} \\
(\mathrm{mg} / \mathrm{g})\end{array}$ & $\begin{array}{c}K_{d} \\
(\mathrm{~L} / \mathrm{g})\end{array}$ & $I F$ & $\begin{array}{c}C_{p} \\
(\mathrm{mg} / \mathrm{g})\end{array}$ & $\begin{array}{c}K_{d} \\
(\mathrm{~L} / \mathrm{g})\end{array}$ & $\begin{array}{c}C_{p} \\
(\mathrm{mg} / \mathrm{g})\end{array}$ & $\begin{array}{c}K_{d} \\
(\mathrm{~L} / \mathrm{g})\end{array}$ & IF \\
\hline $\mathrm{BzP}$ & 3.10 & 1.13 & 2.74 & 0.86 & 1.25 & 3.68 & 1.33 & 3.34 & 0.93 & 1.44 \\
\hline $\mathrm{BuP}$ & 2.74 & 0.79 & 2.71 & 0.77 & 1.04 & 3.49 & 1.08 & 3.39 & 0.81 & 1.33 \\
\hline $\operatorname{PrP}$ & 2.72 & 0.78 & 2.64 & 0.71 & 1.09 & 3.41 & 1.13 & 3.14 & 0.85 & 1.34 \\
\hline EtP & 2.61 & 0.76 & 2.33 & 0.83 & 0.92 & 2.95 & 0.50 & 2.64 & 0.39 & 1.27 \\
\hline $\mathrm{MeP}$ & 2.55 & 0.62 & 2.49 & 0.58 & 1.07 & 2.55 & 0.58 & 2.53 & 0.58 & 1.01 \\
\hline
\end{tabular}


The binding capacities of RAFT-MIPs and MIPs, which had higher affinity capacities than RAFT-NIPs and NIPs, were further investigated using the binding isotherms and Scatchard analyses. Figure 8 shows that the binding isotherms of RAFT-MIPs and MIPs for BzP were determined to be in the range of $10-250 \mathrm{mg} / \mathrm{L}$. It can be seen that the amount of BzP uptake for all MIPs increased as the concentration increased. The binding capacity of RAFT-MIP1 exceeded MIP1, but the binding capacity of RAFT-MIP2 was lower than MIP2.

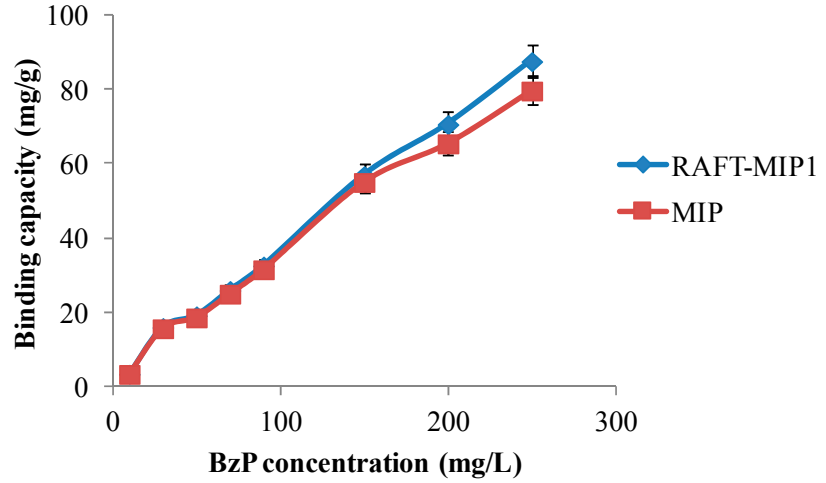

(a)

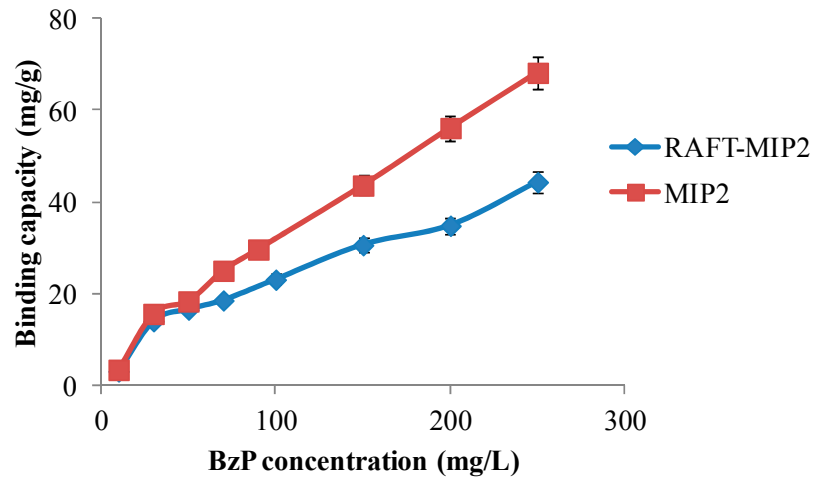

(b)

Figure 8. Binding isotherms of (a) RAFT-MIP1 and MIP; and (b) RAFT-MIP2 and MIP2.

The obtained binding data were plotted using the Scatchard equation to estimate the dissociation constant, $K_{d}$, and the apparent maximum number of binding sites, $C_{p m a x}$. The Scatchard equation is as shown below [58]:

$$
C_{p} / C_{f}=C_{p \max }-\left(C_{p} / K_{d}\right)
$$

As shown in Figure 9, there were two distinct sections within the plot that could be regarded as straight lines. The results indicated that there were two classes of binding sites in MIPs polymers, suggesting a heterogeneous system. From the slope and the intercept of the plot, the equilibrium dissociation constant $K_{d}$ and the apparent maximum number $C_{p m a x}$ of the affinity binding sites were calculated (see Table 4).

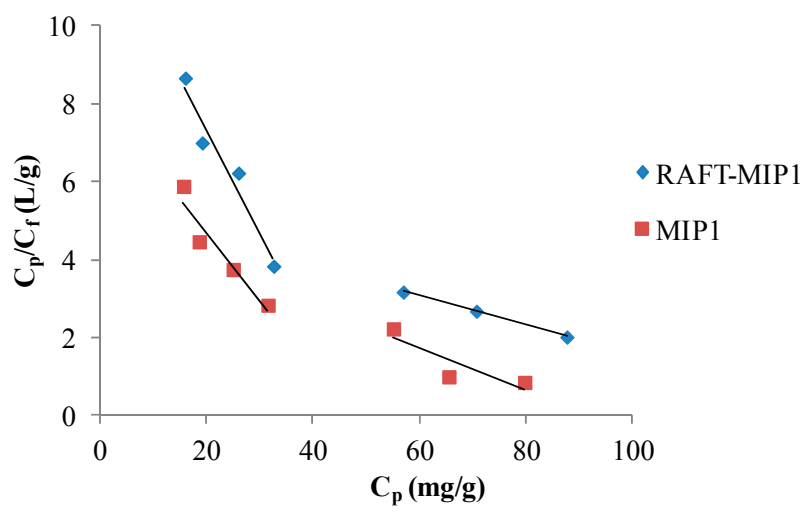

(a)

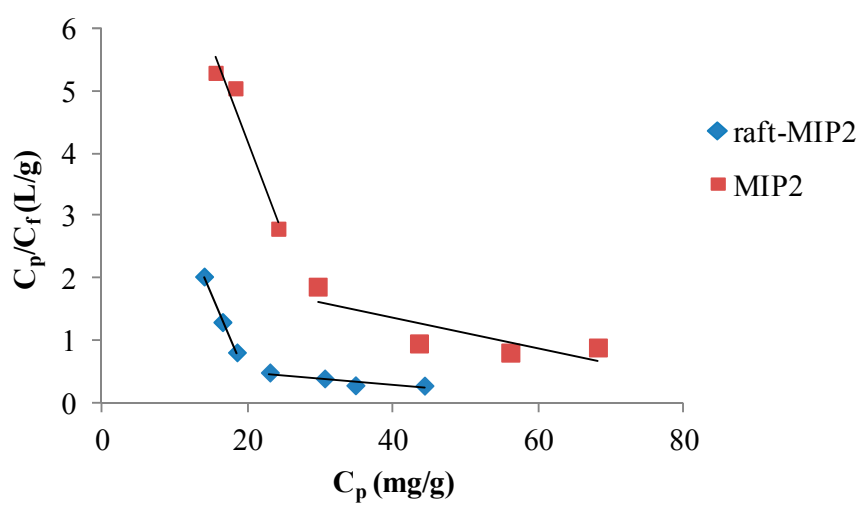

(b)

Figure 9. Scatchard plot of (a) RAFT-MIP1 and MIP1; and (b) RAFT-MIP2 and MIP2. 
Table 4. The apparent maximum number, $C_{p m a x}$ and the equilibrium dissociation constant, $K_{d}$.

\begin{tabular}{ccccc}
\hline MIPs & The Linear Regression Equation & $\boldsymbol{R}^{\mathbf{2}}$ & $\boldsymbol{C}_{\boldsymbol{p m a x}}(\mathbf{m g} / \mathbf{g})$ & $\boldsymbol{K}_{\boldsymbol{d}}$ \\
\hline \multirow{2}{*}{ RAFT-MIP1 } & (high binding affinity) $C_{p} / C_{f}=-0.2648 C_{p}+12.643$ & 0.9478 & 47.75 & 3.78 \\
& (low binding affinity) $C_{p} / C_{f}=-0.0376 C_{p}+5.3206$ & 0.9994 & 141.51 & 26.60 \\
\hline \multirow{2}{*}{ MIP1 } & (high binding affinity) $C_{p} / C_{f}=-0.1741 C_{p}+8.1928$ & 0.9108 & 47.03 & 5.74 \\
& (low binding affinity) $C_{p} / C_{f}=-0.0532 C_{p}+4.9131$ & 0.7557 & 92.35 & 18.80 \\
\hline \multirow{2}{*}{ RAFT-MIP2 } & (high binding affinity) $C_{p} / C_{f}=-0.2698 C_{p}+5.7916$ & 0.9976 & 21.47 & 3.71 \\
& (low binding affinity) $C_{p} / C_{f}=-0.1030 C_{p}+0.7028$ & 0.8273 & 6.82 & 9.71 \\
\hline \multirow{2}{*}{ MIP2 } & (high binding affinity) $C_{p} / C_{f}=-0.1691 C_{p}+8.0157$ & 0.9824 & 47.40 & 5.91 \\
& (low binding affinity) $C_{p} / C_{f}=-0.0245 C_{p}+2.3405$ & 0.6762 & 95.53 & 40.82 \\
\hline
\end{tabular}

In summary, the effect of RAFT agent led to dissimilar performance of binding capacity in both imprinted polymers of MAA- $\beta-C D$ and HEMA- $\beta-C D$. As described previously, the RAFT agent stabilized the mechanism of MAA polymerization, which was helpful for the accessibility and availability of the recognition sites. It also possessed excellent binding ability, more selectivity, and more affinity to the targeted analyte. This was in contrast with the imprinted polymer of HEMA- $\beta-C D$, as the RAFT-MIP2 had a slightly lower binding capacity than MIP2. Consequently, the RAFT agent was not always a benefit to MIP synthesis; it was found to be a limitation in certain contexts, affecting the adsorption ability and lessening the affinity binding.

\section{Conclusions}

The imprinted polymers of MAA- $\beta-C D$ and HEMA- $\beta-C D$, synthesis via RAFT and TRP polymerization processes were investigated in this study. FESEM and BET characterization have proven the effect of RAFT agent in MIP polymerization processes. The adsorption ability of the MIPs was evaluated by binding isotherms and Scatchard analyses. As for RAFT-MIP(MAA- $\beta$-CD) synthesis, the RAFT agent did not only affects the morphology of the polymer, but it also help to improve the imprinting polymer properties, especially in selectivity and affinity. Unfortunately, the role of RAFT agent on RAFT-MIP(HEMA- $\beta-C D)$ synthesis was poor on the imprinting binding. It can be concluded that the effectiveness of a RAFT agent depends on the monomer used. Careful choice of a RAFT agent and monomer is imperative in realizing excellent control over the MIP polymerization process and crucial for generating successful MIPs.

\section{Supplementary Materials}

Supplementary materials can be accessed at: http://www.mdpi.com/2073-4360/7/03/0484/s1.

\section{Acknowledgments}

We gratefully acknowledge the University of Malaya for the Postgraduate Research Fund IPPP Grant (PV015-2011A), the Research Grant (UMRG) program (RP006A-13SUS), and the High Impact Research Grant (HIR) UM HIR/MOHE /SC/F00031 from the Ministry of Higher Education Malaysia (MOHE). 


\section{Author Contributions}

Saliza Asman, Sharifah Mohamad, and Norazilawati Muhamad Sarih designed the research; Saliza Asman and Sharifah Mohamad performed the research and analyzed the data; Saliza Asman, Sharifah Mohamad, and Norazilawati Muhamad Sarih wrote the manuscript. All authors read and approved the final manuscript.

\section{Conflicts of Interest}

The authors declare no conflicts of interest.

\section{References}

1. Andersson, L.I.; Nicholls, I.A.; Mosbach, K. Molecular imprinting: The current status and future development of polymer-based recognition system. Adv. Mol. Cell Biol. 1996, 15, 651-670.

2. Yan, H.; Row, K.H. Characteristic and synthetic approach of molecularly imprinted polymer. Int. J. Mol. Sci. 2006, 7, 155-178.

3. Yusof, N.A.; Rahman, S.K.A.; Hussein, M.Z.; Ibrahim, N.A. Preparation and characterization of molecularly imprinted polymer as SPE sorbent for melamine isolation. Polymers 2013, 5, 1215-1228.

4. Wackers, G.; Vandenryt, T.; Cornelis, P.; Kellens, E.; Thoelen, R.; Ceuninck, W.D.; Losada-Pérez, P.; Grinsven, B.V.; Peeters, M.; Wagner, P. Array formatting of the heat-transfer method (HTM) for the detection of small organic molecules by molecularly imprinted polymers. Sensors 2014, 14, 11016-11030.

5. Alexander, C.; Davidson, L.; Hayes, W. Imprinted polymers: Artificial molecular recognition materials with applications in synthesis and catalysis. Tetrahedron 2003, 59, 2025-2057.

6. Asman, S.; Yusof, N.A.; Abdullah, A.H.; Haron, M.J. Synthesis and characterization of hybrid molecularly imprinted polymer (MIP) membranes for removal of methylene blue. Molecules 2012, 17, 1916-1928.

7. Wang, A.R.; Zhu, S. Branching and gelatine in atom transfer radical polymerization of methyl methacrylate and ethylene glycol dimethacrylate. Polym. Eng. Sci. 2005, 5, 720-727.

8. Watabe, Y.; Hosoya, K.; Tanaka, N.; Kubo, T.; Morita, M. Novel surface modified molecularly imprinted polymer focused on the removal of interference in environmental water samples for chromatographic determination. J. Chromatorgr. A 2005, 1073, 363-370.

9. Pan, G.; Zu, B.; Guo, X.; Zhang, Y.; Li, C.; Zhang, H. Preparation of molecularly imprinted polymer microspheres via reversible addition-fragmentation chain transfer precipitation polymerization. Polymer 2009, 50, 2819-2825.

10. Goto, A.; Kukuda, T. Kinetics of living radical polymerization. Prog. Polym. Sci. 2004, 29, 329-385.

11. Hawker, C.J. Living free radical polymerization: A unique technique for the preparation of controlled macromolecular architectures. Acc. Chem. Res. 1997, 30, 373-382.

12. Matyjaszewski, K.; Spanswick, J. Controlled/living radical polymerization. Mater. Today 2005, 8 , 26-33.

13. Zu, B.; Pan, G.; Guo, X.; Zhang, Y.; Zhang, H. Preparation of Molecularly imprinted polymer microspheres via atom transfer radical precipitation polymerization. J. Polym. Sci. A Polym. Chem. 2009, 47, 3257-3270. 
14. Peeters, M.; Kobben, S.; Jiménez-Monroy, K.L.; Modesto, L.; Kraus, M.; Vandenryt, T.; Gaulke, A.; van Grinsven, B.; Ingebrandt, S.; Junkers, T.; et al. Thermal detection of histamine with a graphene oxide based molecularly imprinted polymer platform prepared by reversible addition-fragmentation chain transfer polymerization. Sens. Actuators B Chem. 2014, 203, 527-535.

15. Hu, X.; Fan, Y.; Zhang, Y.; Dai, G.; Cai, Q.; Cao, Y.; Guo, C. Molecularly imprinted polymer coated solid-phase microextraction fiber prepared by surface reversible addition-fragmentation chain transfer polymerization for monitoring of Sudan dyes in chilli tomato sauce and chilli pepper samples. Anal. Chim. Acta 2012, 731, 40-48.

16. Zhang, Y.; Ding, J.; Gong, S. Preparation of molecularly imprinted polymers for vanillin via reversible addition-fragmentation chain transfer suspension polymerization. Appl. Polym. Sci. 2012, 128, 2927-2932.

17. Xu, S.; Li, J.; Chen, L. Molecularly imprinted polymers by reversible addition-fragmentation chain transfer precipitation polymerization for preconcentration of atrazine in food matrices. Talanta 2011, 85, 282-289.

18. Dai, J.; Pan, J.; Xu, L.; Li, X.; Zhou, Z.; Zhang, R.; Yan, Y. Preparation of molecularly imprinted nanoparticles with supermagnetic susceptibility through atom transfer radical emulsion polymerization for the selective recognition of tetracycline from aqueous medium. J. Hazard. Mater. 2012, 205-206, 179-188.

19. Li, Y.; Li, X.; Chu, J.; Dong, C.; Qi, J.; Yuan, Y. Synthesis of core-shell magnetic molecular imprinted polymer by the surface RAFT polymerization for the fast and selective removal of endocrine disrupting chemicals from aqueous solutions. Environ. Pollut. 2010, 158, 2317-2323.

20. Lu, C.-H.; Zhou, W.-H.; Han, B.; Yang, H.-H.; Chen, X.; Wang, X.-R. Surface-imprinted core-shell nanoparticles for sorbent assays. Anal. Chem. 2007, 79, 5457-5461.

21. Xu, S.; Li, J.; Chen, L. Molecularly imprinted core-shell nanoparticles for determination of trace atrazine by reversible addition-fragmentation chain transfer surface imprinting. J. Mater. Chem. 2011, 21, 4345-4351.

22. Boonpangrak, S.; Whitcombe, M.J.; Prachayasittikul, V.; Mosbach, K.; Ye, L. Preparation of molecularly imprinted polymers using nitroxide-mediated living radical polymerization. Biosen. Bioelectron. 2006, 22, 349-354.

23. Sasaki, S.; Ooya, T.; Takeuchi, T. Highly selective bisphenol A-imprinted polymers prepared by atom transfer radical polymerization. Polym. Chem. 2010, 1, 1684-1688.

24. Vaughan, A.D.; Sizemore, S.P.; Byrne, M.E. Enhancing molecularly imprinted polymer binding properties via controlled/living radical polymerization and reaction analysis. Polymer 2007, 48, 74-81.

25. Pérez-Moral, N.; Mayes, A.G. Comparative study of imprinted polymer particles prepared by different polymerisation methods. Anal. Chim. Acta 2004, 504, 15-21.

26. Zu, B.; Zhang, Y.; Guo, X.; Zhang, H. Preparation of molecularly imprinted polymers via atom transfer radical "bulk" polymerization. J. Polym. Chem. 2010, 48, 532-541.

27. Ma, Y.; Pan, G.; Zhang, Y.; Guo, X.; Zhang, H. Comparative study of the molecularly imprinted polymers prepared by reversible addition-fragmentation chain transfer "bulk" polymerization. J. Mol. Recognit. 2013, 26, 240-251.

28. Moad, G. RAFT (Reversible addition-fragmentation chain transfer) crosslinking (co)polymerization of multi-olefinic monomers to form polymer networks. Polym. Int. 2014, 64, 15-24. 
29. Chiefari, J.; Chong, Y.K.; Ercole, F.; Krstina, J.; Jeffery, J.; Le, T.P.T.; Mayagunne, R.T.A.; Meijs, G.F.; Moad, C.L.; Moad, G.; et al. Living free-radical addition-fragmentation chain transfer: The RAFT process. Macromolecules 1998, 31, 5559-5562.

30. Barsbay, M.; Güven, O.; Stenzel, M.H.; Davis, T.P.; Barner-Kowollik, C.; Barner, L. Verification of controlled grafting of styrene from cellulose via radiation-induced RAFT polymerization. Macromolecules 2007, 40, 7140-7147.

31. Moad, G.; Rizzardo, E.; THang, S.H. Living radical polymerization by the RAFT process. Aust. J. Chem. 2005, 58, 379-410.

32. Harrisson, S.; Liu, X.; Ollagnier, J.-N.; Coutelier, O.; Marty, J.-D.; Destarac, M. RAFT polymerization of vinyl esters: Synthesis and applications. Polymers 2014, 6, 1437-1488.

33. Cormack, P.A.G.; Mehamod, F.S. Molecularly imprinted polymer synthesis using RAFT polymerization. Sains Malays. 2013, 42, 529-535.

34. Wei, Z.; Hao, X.; Kambouris, P.A.; Gan, Z.; Hughes, T.C. One-pot synthesis of hyperbranched polymers using small molecule and macro RAFT inimers. Polymer 2012, 53, 1429-1436.

35. Wang, Z.; He, J.; Tao, Y.; Yang, L.; Jiang, H.; Yang, Y. Controlled chain branching by RAFT-based radical polymerization. Macromolecules 2013, 36, 7446-7452.

36. Carter, S.; Rimmer, S.; Sturdy, A.; Webb, M. Highly branched stimuli responsive Poly[( $N$-isopropyl acrylamide)-co-(1,2-propandiol-3-methacrylate) $] \mathrm{s}$ with protein binding functionality. Macromol. Biosci. 2005, 5, 373-378.

37. Liu, B.; Kazlauciunas, A.; Guthrie, J.T.; Perrier, S. Influence of reaction parameters on the synthesis of hyperbranched polymers via reversible addition fragmentation chain transfer (RAFT) polymerization. Polymer 2005, 46, 6293-6299.

38. Titirici, M.-M.; Sellergren, B. Thin molecularly imprinted polymer films via reversible addition-fragmentation chain transfer polymerization. Chem. Mater. 2006, 18, 1773-1779.

39. Southard, G.E.; van Houten, K.A.; Ott, E.W., Jr.; Murray, G.M. Luminescent sensing of organophosphates using europium (III) containing imprinted polymers prepared by RAFT polymerization. Anal. Chim. Acta 2007, 581, 202-207.

40. Achilleos, M.; Legge, T.M.; Perrier, S.; Patrickios, C.S. Poly(ethylene glycol)-based amphiphilic model conetworks: Synthesis by RAFT polymerization and characterization. J. Polym. Sci. A Polym. Chem. 2008, 46, 7556-7565.

41. Krasia, T.; Patrickios, C.S. Amphiphilic polymethacrylate model co-networks: Synthesis by RAFT radical polymerization and characterization of the swelling behaviour. Macromolecules 2006, 39, 2467-2473.

42. Szejtli, J. Introduction and general overview of cyclodextrin chemistry. Chem. Rev. 1998, 98, 1743-1754.

43. Xu, Z.; Kuang, D.; Liu, L.; Deng, Q. Selective adsorption of norfloxacin in aqueous media by an imprinted polymer based on hydrophobic and electrostatic interactions. J. Pharm. Biomed. Anal. 2007, 45, 54-61.

44. Asman, S.; Mohamad, S.; Sarih, N.M. Exploiting $\beta$-cyclodextrin in molecular imprinting for achieving recognition of benzylparaben in aqueous media. Int. J. Mol. Sci. 2015, 16, 3656-3676.

45. Sreenivasan, K. Grafting of $\beta$-cyclodextrin-modified 2-hydroxyethyl methacrylate onto polyurethane. J. Appl. Polym. Sci. 1996, 60, 2245-2249. 
46. Mohamad, S.; Yusof, N.H.M.; Asman, S. Effect of bifunctional isocyanate linker on adsorption of chromium (IV) diphenylcarbazide complex onto $\beta$-cyclodextrin. Asian J. Chem. 2013, 25, 2213-2220.

47. Spivak, D.A. Optimization, evaluation and characterization of molecularly imprinted polymers. Adv. Drug Deliv. Rev. 2005, 57, 1779-1794.

48. Kania, N.; Rio, S.; Monflier, E.; Ponchel, A. Cyclodextrin adsorbed onto activated carbons: Preparation, characterization and effect on the dispersibility of the particles in water. J. Colloid Interface Sci. 2012, 371, 89-100.

49. Alahmadi, S.M.; Mohamad, S.; Maah, M.J. Synthesis and characterization of mesoporous silica functionalized with calix[4] arene derivatives. Int. J. Mol. Sci. 2012, 13, 13726-13736.

50. Li, Y.; Du, Q.; Liu, T.; Sun, J.; Jiao, Y.; Xia, Y.; Xia, L.; Wang, Z.; Zhang, W.; Wang, K.; et al. Equilibrium, kinetic and thermodynamic studies on the adsorption of phenol onto graphene. Mater. Res. Bull. 2012, 47, 1898-1904.

51. Wilson, L.D.; Mohamed, M.H.; Headley, J.V. Surface area and pore structure properties of urethane- based copolymers containing $\beta$-cyclodextrin. J. Colloid Interface Sci. 2011, 357, $215-222$.

52. Asouhidou, D.D.; Triantafyllidis, K.S.; Lazaridis, N.K.; Matis, K.A. Adsorption of remazol red 3BS from aqueous solutions using APTES- and cyclodextrin-modified HMS-type mesoporous silicas. Colloids Surf. A 2009, 346, 83-90.

53. Mena-Duran, C.J.; Kou, M.S.; Lopez, T.; Azamar-Barrios, J.A.; Aguilar, D.H.; Domínguez, M.I.; Odriozola, J.A.; Quintana, P. Nitrate removal using natural clays modified by acid thermoactivation. Appl. Surf. Sci. 2007, 253, 5762-5766.

54. Sing, K.S.W.; Everett, D.H.; Haul, R.A.W.; Moscou, L.; Pierotti, R.A.; Rouquerol, J.; Siemieniewska, T. Reporting physisorption data for gas/solid systems with special reference to the determination of surface area and porosity (Recommendation 1984). Pure Appl. Chem. 1985, 57, 603-619.

55. Idris, S.A.; Alotaibi, K.M.; Peshkur, T.A.; Anderson, P.; Morris, M.; Gibson, L.T. Adsorption kinetic study: Effect of adsorbent pore size distribution on the rate of $\mathrm{Cr}$ (VI) uptake. Microporous. Mesoporous. Mater. 2013, 165, 99-105.

56. Holland, N.; Frisby, J.; Owens, E.; Hughes, H.; Duggan, P.; McLoughlin, P. The influence of polymer morphology on the performance of molecularly imprinted polymers. Polymer 2010, 51, $1578-1584$.

57. Xu, Z.; Xu, L.; Kuang, D.; Zhang, F.; Wang, J. Exploiting $\beta$-cyclodextrin as functional monomer in molecular imprinting for achieving recognition in aqueous media. Mater. Sci. Eng. C 2008, 28, $1516-1521$.

58. Matsui, J.; Miyoshi, Y.; Doblhoff-Dier, O.; Takeuchi, T. A molecularly imprinted synthetic polymer receptor selective for atrazine. Anal. Chem. 1995, 67, 4404-4408.

(C) 2015 by the authors; licensee MDPI, Basel, Switzerland. This article is an open access article distributed under the terms and conditions of the Creative Commons Attribution license (http://creativecommons.org/licenses/by/4.0/). 